ARTIGOS

\title{
Onde tem fada, tem bruxa': posições de sujeito usadas para classificar e governar infantis e docente no currículo do $1^{\circ}$ ano
}

\section{Where there is a fairy, there is always a witch: revealed subject positions and scoping of children and teachers in the children literacy curriculum}

Maria Carolina da Silva Caldeira ${ }^{\mathrm{i}}$ Marlucy Alves Paraíso ii

iCentro Pedagógico da Escola de Educação Básica e Profissional, Universidade Federal de Minas Gerais - UFMG, Belo Horizonte, MG, Brasil.mariacarolsilva@gmail.com.

ii Faculdade de Educação, Universidade Federal de Minas Gerais - UFMG, Belo Horizonte, MG, Brasil.marlucy@paraiso.pro.

Resumo
Fadas e bruxas estão presentes no universo da alfabetização em diferentes
artefatos culturais. Ao investigar o currículo de uma turma de primeiro ano do
Ensino Fundamental, foi possível verificar que bruxas e fadas estão presentes
também no modo como uma professora e seus (suas) alunos(as) narram a si
mesmos(as) e são narrados(as) pelos(as) outros(as). Este artigo analisa os
modos de subjetivação colocados em funcionamento no currículo, quando se
opera com esses seres mágicos, por meio da articulação e da disputa entre dois
dispositivos: o da antecipação da alfabetização e o de infantilidade. Argumenta-
se que, assim como fadas e bruxas são personagens ambíguos, as posições de
sujeito disponibilizadas aos (às) infantis e à professora também são
multifacetadas, produzindo modos de subjetivação diversos e conflitantes.
Palavras-chave: currículo, alfabetização, posições de sujeito, dispositivo de
infantilidade

1 O título faz menção a uma obra de Bartolomeu Campos de Queirós, que tem um trecho apresentado no livro didático da turma (Queirós, 1988). 


\section{Abstract}

Fairies and witches are present in the universe of literacy. By investigating the curriculum of a $1^{\text {st }}$ grade class of the Fundamental Education, it was found that witches and fairies are also present in the way a teacher and their students recount themselves and are recounted by the others. This article analyzes the modes of subjectivity set into action in the curriculum when dealing with these magical beings. The production of subjects takes place in the handling and dispute between two devices: the anticipation of literacy and childishness. It is argued that, since fairies and witches are ambiguous characters in the stories in which they appear, the subject positions available to children and the teacher are also multifaceted, producing diverse and conflicting modes of subjectivity.

Keywords: curriculum, literacy, subject positions, childishness device

O que a alfabetização tem a ver com mágica, feitiços e bruxarias? É certo que fadas, bruxas e outros seres mágicos que realizam essas práticas estão nos diferentes artefatos culturais presentes no contexto da alfabetização. Esses seres mágicos foram vistos diversas vezes na pesquisa que dá base a este artigo e que investigou, ao longo do ano de 2013, uma turma de primeiro ano do Ensino Fundamental da rede municipal de Belo Horizonte, para compreender os efeitos que a antecipação da alfabetização para 6 anos tem no currículo e nos modos de subjetivação docentes e infantis. Como metodologia de pesquisa, foram utilizados elementos da etnografia de inspiração pós-moderna (Caldeira, 1988) e da análise de discurso foucaultiana.

A etnografia de inspiração pós-moderna refere-se a um conjunto de estudos que têm procurado afastar-se tanto das perspectivas clássicas e estruturalistas da antropologia como de perspectivas hermenêuticas. As perspectivas etnográficas pós-modernas partem do "caráter seletivo e parcial da 'verdade' antropológica" [ênfase no original] (Caldeira, 1988, p. 147) e do princípio de que os textos etnográficos produzidos estão envolvidos em relações de poder, que, por sua vez, atuam na produção de verdades sobre os grupos culturais pesquisados. Também consideram que o texto etnográfico é sempre uma 


\section{pro.posições}

produção do(a) pesquisador(a), que não deve se ausentar do texto e deve deixar claro que foi a sua perspectiva que produziu aquelas informações sobre o grupo pesquisado (Clifford, 2008). Ponderam, ainda, que não há um significado profundo escondido nas práticas culturais, mas todos os significados são produzidos nas relações estabelecidas, sendo possível acessá-los, descrevê-los e analisá-los, sem recorrer a uma essência (Rabinow, 2002) ou a um significado profundo, último ou oculto.

Com base nos princípios teóricos da etnografia pós-moderna, foram realizadas observações da turma selecionada durante um ano. Além das aulas, também acompanhamos e registramos os momentos de recreio, as festas e os eventos escolares, as reuniões pedagógicas, as atividades de reforço para os(as) alunos(as) que não estavam alfabetizados(as) no segundo semestre de 2013 e os momentos de planejamento das atividades realizadas pela docente da turma. As informações coletadas foram registradas em diário de campo e analisadas com base na análise de discurso foucaultiana. Nesse sentido, procuramos compreender os discursos que ali circulavam, as relações de poder estabelecidas, as estratégias, as técnicas e as táticas desenvolvidas pela professora e pelos(as) alunos(as).

Durante essas observações, seres mágicos eram vistos às vezes de forma mais intensa, outras de maneira mais sutil. Eles apareciam nos livros de literatura infantil disponíveis na biblioteca da escola ${ }^{2}$ e nas revistas em quadrinhos que circulavam na sala de aula. Estavam também nos livros didáticos e nos textos entregues às crianças ${ }^{3}$. Ilustravam capas de cadernos, lápis, adesivos, roupas e sapatos dos(as) alunos(as) ${ }^{4}$. Surgiam também nas conversas infantis. Eram utilizados como elementos de técnicas e táticas para a produção de modos de ser aluno(a) e professora. Tudo isso evidencia que o currículo é habitado por esses "seres mágicos".

\footnotetext{
2 Alguns desses livros serão analisados ao longo deste artigo.

3 Textos usados na sala com a temática fadas ou bruxas e trechos do livro didático que tinham esses seres como tema foram trabalhados em diversos momentos na turma e serão analisados neste artigo.

${ }^{4}$ Nos cadernos, nos lápis e nas vestimentas havia a presença da fada Tinker Bell (Sininho), que se tornou mais popular graças aos filmes da Disney em que aparece como protagonista. Até agora, foram lançados cinco filmes: Tinker Bell - Uma Aventura no mundo das fadas (2008), Tinker Bell e o tesouro perdido (2009), Tinker Bell e o resgate da fada (2010), Tinker Bell - o segredo das fadas (2013) e Tinker Bell: fadas e piratas (2014). O penúltimo filme foi exibido no cinema para as crianças da escola em que foi feita a pesquisa em comemoração ao dia das crianças (Diário de campo, 07 de outubro de 2013). Outras fadas também estavam presentes em adesivos e cadernos.
} 


\section{pro.posições}

Currículo é entendido neste artigo como um "um discurso que, ao corporificar narrativas particulares sobre o indivíduo e a sociedade, nos constitui como sujeitos" (Silva, 1995, p. 195). Trata-se de um espaço de ensino, de experimentações, de vivências e de práticas que estão envolvidos em relações de poder-saber. Consideramos que nesse espaço operam dispositivos, tecnologias e técnicas que, muitas vezes, evidenciam conflitos culturais, políticos e discursivos, ao mesmo tempo em que disponibilizam diferentes modos de ser, estar e viver para os(as) envolvidos(as) no processo de ensino-aprendizagem. Para nós, um currículo é, também, uma construção social que "produz ideias, práticas coletivas e individuais, sujeitos que existem, vivem, sofrem e alegram-se, num mundo que se produz atravessado por complexas redes de relações" (Corazza, 2001, p. 14). Julgamos que, ao incorporar certos saberes, conhecimentos, práticas e construir determinadas relações de poder, "suas narrativas e significados ensinam, formam e produzem sujeitos de determinados tipos" (Paraíso, 2010a, p. 12).

Cabe registrar também que, na perspectiva de currículo aqui adotada, tomamos cada currículo como único, e, por isso, uma "grande diversidade de respostas são encontradas nas investigações" (Paraíso, 2010a, p. 12). Cada currículo "se conecta de modos distintos, com tempos, espaços, saberes, culturas e pessoas, nos diferentes espaços por onde circula" (Paraíso, 2010a, p. 12). Não procuramos, então, por respostas unívocas, nem por princípios que possam ser aplicáveis em diferentes contextos, mas buscamos ressaltar o caráter individual de cada currículo, sem desconsiderar a sociedade mais ampla em que ele se insere.

Isso significa que, ao analisar o currículo de uma turma de primeiro ano do Ensino Fundamental de uma escola da rede municipal de Belo Horizonte, defendemos que esse currículo possui características particulares, próprias daquela sala de aula, das relações de poder ali estabelecidas, das estratégias e táticas ali operacionalizadas. Assim, ainda que na escola haja outra turma de primeiro ano do Ensino Fundamental, as práticas desenvolvidas na sala investigada são peculiares e singulares. Cabe registrar também que não entendemos currículo como um documento que seria colocado em prática nas salas de aula. Procuramos analisar aquilo que é vivido em cada contexto particular, privilegiando o que é específico daquela sala de aula e que torna o currículo único. O entendimento de que cada currículo é único torna a análise dessas práticas peculiares fundamental para compreendermos como, apesar das inúmeras políticas e relações de poder que tentam homogeneizar o currículo, há 


\section{pro.posições}

espaço para escapes e criações. Especificamente no caso do currículo investigado, essas peculiaridades faziam com que a magia se apresentasse de forma intensa, produzindo efeitos no currículo, nas crianças e na professora.

É em torno da ideia da professora bruxa ou da alfabetizadora fada que este artigo está organizado. O mote para a análise aqui empreendida é a seguinte fala da professora que participou da investigação: "A professora só é fada quando a criança é fada. Quando a professora é bruxa, é porque a criança é bruxa também". Assim, este artigo analisa os modos de subjetivação da docente alfabetizadora e $\operatorname{dos}(\mathrm{as})$ infantis alfabetizandos(as), colocados em funcionamento no currículo investigado quando se opera com esses seres que tanto fascinam as crianças. Com base na filosofia de Michel Foucault, a expressão "modos de subjetivação" refere-se ao "modo pelo qual um ser humano toma-se um sujeito" (Foucault, 1995, p. 232), ou seja, remete às diversas práticas que formam sujeitos de determinado tipo. Esse processo de produção se dá porque "o sujeito não é uma substância” (Foucault, 2004, p. 275). Por essa razão, ele precisa ser constantemente produzido, montado, fabricado. Nesse sentido, Deleuze (1992) afirma que "sim, existem sujeitos: são grãos dançantes na poeira do visível, e lugares móveis num murmúrio anônimo. O sujeito é sempre uma derivada. Ele nasce e se esvai na espessura do que se diz, do que se vê" (p. 133). Assim, consideramos que, no currículo do primeiro ano do Ensino Fundamental investigado, são disponibilizados modos de subjetivação para infantis e docentes, com vistas a produzi-los de determinada forma.

Há na prática investigada, dessa maneira, um intrincado processo de produção de sujeitos em funcionamento, que vincula as formas de ser docente às formas de ser infantil, demandando posições de sujeito específicas para que a alfabetização das crianças seja garantida. Posições de sujeito referem-se aos modos de ser demandados e produzidos por meio dos discursos e das relações de poder (Foucault, 2004). A produção de posições de sujeitos no currículo investigado se dá por meio da articulação entre dois dispositivos de poder: o dispositivo de antecipação da alfabetização e o dispositivo de infantilidade. Dispositivo é entendido aqui, com base em Foucault (2000), como "um conjunto decididamente heterogêneo que engloba discursos, instituições, organizações arquitetônicas, decisões regulamentares, leis, medidas administrativas, enunciados científicos, proposições filosóficas, morais, filantrópicas" (p. 244), que visa à produção de sujeitos. 
O dispositivo de antecipação da alfabetização, por sua vez, refere-se aos elementos heterogêneos que têm sido utilizados para demandar e justificar que a alfabetização das crianças aconteça o quanto antes, preferencialmente no primeiro ano do Ensino Fundamental nas escolas públicas brasileiras ${ }^{5}$. Ainda que haja políticas como o Pacto Nacional pela Alfabetização na Idade Certa, que defendem que o processo de alfabetização pode se efetivar até o terceiro ano do Ensino Fundamental, o que se percebe é uma busca para que esse processo se efetive o quanto antes. Por essa razão, diferentes pesquisas vêm mostrando como a expansão do Ensino Fundamental tem feito com que o primeiro ano se centre quase exclusivamente na alfabetização.

Pansini e Marin (2011), por exemplo, em pesquisa realizada em Rondônia, mostram como a ênfase no primeiro ano recaía na alfabetização. As pesquisadoras narram a pressão sentida pelas professoras alfabetizadoras para garantir que as crianças soubessem ler e escrever ao final do primeiro ano. Correa (2011) revela situação semelhante em escolas do interior de São Paulo. Paraíso (2014), em pesquisa realizada em Belo Horizonte, evidencia como, na ânsia por alfabetizar o maior número possível de crianças aos 6 anos, ocorre todo um processo de diferenciação e exclusão daquelas crianças que não frequentaram a Educação Infantil já nos primeiros dias de aula. A pesquisadora afirma que, nesse contexto de ânsia voraz por garantir a alfabetização no primeiro ano do Ensino Fundamental, considera-se normal essa diferenciação e exclusão, porque se defende que essas crianças têm condições mínimas para serem alfabetizadas. Na escola em que foi feita a pesquisa que dá base a este artigo, essa ânsia e a pressão por alfabetizar também estão presentes.

Esse não era, contudo, o único dispositivo que atuava naquela escola: também estava presente ali o dispositivo de infantilidade, que concerne ao conjunto de elementos que possibilitou que, a partir do século XVI, os seres nos anos iniciais de vida passassem a ser identificados como crianças. As características que distinguem os(as) adultos(as) das crianças foram, na perspectiva aqui adotada, construídas peça por peça por esse dispositivo, que agiu e continua agindo no sentido de diferenciar e de distinguir adultos(as) de crianças (Corazza, 2002a), disponibilizando distintas posições de sujeitos para infantis e adultos(as).

Ao disponibilizar certas posições de sujeito, esses dispositivos atuam no governo de professoras e crianças, definindo como eles(as) devem se portar, como devem agir, de que

${ }^{5}$ Esse dispositivo atua para, inclusive, garantir que crianças sejam alfabetizadas desde a Educação Infantil, sobretudo na rede privada de ensino. 


\section{pro.posições}

maneira devem se conduzir. Governo pode ser definido como o ato de "conduzir condutas" (Foucault, 1997), ou seja, "estruturar o eventual campo de ação dos outros" (Foucault, 1995, 244). No caso específico desta análise, definir os(as) infantis e a docente ora como bruxas, ora como fadas é tanto um dos mecanismos de atuação do dispositivo de infantilidade (que associa a professora e as crianças ao místico e ao irracional) como uma forma de resistência a esse dispositivo, uma vez que a intuição, a inventividade e a magia possibilitam escapes em relação a esse dispositivo que opera visando à produção de seres tidos como racionais. Da mesma forma, o dispositivo de antecipação da alfabetização também utiliza esses seres para efetivar o governo dos(as) infantis e para garantir que eles(as) sejam alfabetizados(as) ao final do primeiro ano. Porém, a presença desses seres faz com que outros sentidos se apresentem no currículo, desestabilizando o dispositivo de antecipação da alfabetização e permitindo que outros modos de ser criança e docente se apresentem nesse currículo.

Sendo assim, são analisados aqui os saberes e as relações de poder acionados nesse currículo para produzir professoras e crianças que são ora bruxas, ora fadas. Argumentamos que, assim como fadas e bruxas são personagens ambíguas nas diferentes histórias em que aparecem, as posições de sujeito disponibilizadas para infantis e para a professora alfabetizadora também são multifacetadas, produzindo e demandando diferentes, complementares e conflitantes posições de sujeito, associadas a esse mundo fantástico das mágicas e dos feitiços. Nesse contexto, ser infantil-fada significa assumir uma posição de sujeito aluno(a)-disciplinado(a), enquanto o(a) infantil-bruxo(a) representa a posição de sujeito aluno(a)-levado(a). ${ }^{6}$ Porém, às vezes, o(a) infantil-fada também pode ser nomeado(a) como menos capaz do que o(a) infantil bruxo(a), que assume o lugar daquele(a) que foge às regras e, por isso, faz mágicas e inventa outro modo de ser criança no processo de alfabetização. Além disso, a docente alfabetizadora-fada pode ser tanto aquela que assume a posição de sujeito amoroso e afetivo, como a que, justamente por assumir essa posição, se sobrecarrega em meio a tantas atividades e demandas. Já a professora-bruxa assume a posição de sujeito docente-rígido, mas também faz feitiços e bruxarias que encantam os(as) infantis (fadas e bruxos[as]), provocando aprendizagens diversas no currículo investigado. Dessa forma, entre fadas e bruxas no currículo do

\footnotetext{
${ }^{6} \mathrm{Na}$ nomeação dessas duas posições de sujeito, utilizamos a expressão “aluno(a)", por considerar que essas são demandas específicas da instituição escolar que procura transformar as crianças em alunos(as). Quando nos referimos, porém, a escapes em relação às normas escolares, procuramos utilizar "infantil" ou "criança", para enfatizar que se trata de produções discursivas não vinculadas exclusivamente à escola.
} 


\section{pro.posıções}

primeiro ano do Ensino Fundamental pesquisado, produzem-se diferentes modos de ser infantil alfabetizando e professora alfabetizadora.

\section{A professora rígida e o infantil levado: uma bruxa malvada para conduzir os(as) infantis?}

$\mathrm{Na}$ cultura ocidental, bruxas são, de modo geral, associadas à maldade. Como aponta Corazza (2002b), elas foram vinculadas aos maus agouros, ao que há de errado, à perdição. $\mathrm{Na}$ literatura infantojuvenil e em vários filmes dela decorrentes, as bruxas assumem essa posição: a Bruxa Má da história da Branca de Neve e os sete anões; a Malévola de A Bela Adormecida; Úrsula, a Bruxa do Mar de A Pequena Sereia; a velha cega de João e Maria" são apenas alguns exemplos de como elas são apresentadas nos chamados "contos de fada" que, apesar desse nome, têm nas bruxas sua atração principal. Afinal, são elas que fazem a história acontecer. É a partir de algum ardil por elas construído que a aventura tem início. Ainda que, na maioria das vezes, seu destino seja trágico, são as bruxas que fazem com que a narrativa ocorra.

De modo semelhante, no currículo investigado é a professora-bruxa que faz com que a ação se desenrole. É a partir de suas falas, das atividades por ela propostas, dos seus comandos, que a aula se desenvolve. A professora-bruxa traça a rotina, seja dizendo o que aconteceria naquele dia, seja escrevendo no quadro-negro os passos a serem seguidos, como quando ela redigiu o que ocorreria na aula, escrevendo a "Rotina": 1) Educação Física; 2) Português; 3) Recreio; 4) História; 5) Matemática; 6) Hora do Brinquedo (Diário de campo, 17 de agosto de 2013). É a professora-bruxa que define os passos a serem seguidos nas diferentes atividades. Suas palavras mágicas fazem com que ações sejam desenvolvidas na sala de aula, como quando instrui: "não esquece de fazer bolinha, bolinha, x antes de copiar a parlenda e de colocar a data" (Diário de campo, 24 de abril de 2013). Ela estabelece as regras do espaço escolar, os "combinados" e as "punições" para

\footnotetext{
7 Diferentes versões desses contos de fadas estavam disponíveis para as crianças na biblioteca. Exercia sobre elas um fascínio especial a versão que trazia personagens da "Turma da Mônica" nos papéis dos personagens clássicos. Isso gerava até mesmo conflito, como quando Juliana e Julia discutiram na biblioteca porque ambas queriam o livro A Bela Adormecida (Diário de campo, 30 de maio de 2013). É importante destacar que, respeitando as regras do Comitê de Ética em Pesquisa e os acordos feitos com os(as) pesquisados(as), todos os nomes aqui presentes são fictícios.
} 


\section{pro.posições}

aqueles(as) que não fazem o que é pedido. Sua mágica nesse momento é tentar garantir a ordem e gerir o processo educativo da forma estabelecida naquele espaço. Para isso, ela precisa conduzir os(as) infantis que alternam, sendo ora bruxos(as) (no sentido de que desrespeitavam as regras), ora fadas dóceis, que seguem o que estava proposto.

Nesses momentos entra em cena uma bruxa muito conhecida nos diferentes artefatos em que essas personagens aparecem e também em diferentes currículos escolares: a bruxa-rígida. Esta se caracteriza pela seriedade, pela rigidez e pela assertividade com que conduz as ações em sala de aula. Cabe registrar que a professora rígida está presente em diferentes livros infantis, como naqueles analisados na coletânea organizada por Silveira (2002). Outro exemplo da rigidez da professora, particularmente quando ela é associada às bruxas, é a série de livros Harry Potter, em que todos(as) os(as) docentes são bruxos(as) e, na grande maioria dos casos, são extremamente rígidos no que concerne ao cumprimento das regras (Silva, 2005). Essa rigidez faz com que a professora estabeleça as regras e se empenhe para que elas sejam cumpridas. Essa característica leva a professora a autonomear-se como bruxa. Ser a responsável por garantir que a sala fique em ordem e que as crianças se comportem conforme o estabelecido, deixando de lado suas características infantis e agindo como alunos(as), é uma das ações que - nesse currículo - precisa ser executada pela professora-bruxa.

O enquadramento nessa posição de sujeito, porém, é considerado não apenas uma característica docente, mas uma resposta ao modo como as crianças se comportam na escola. Mais do que uma característica da professora, trata-se de uma conduta adotada para "conduzir condutas" infantis (Foucault, 1997). Na articulação do dispositivo de infantilidade com o dispositivo da antecipação da alfabetização acionados nesse currículo, “a professora só é bruxa quando a criança é bruxa” (Diário de campo, 02 de julho de 2013), ou seja, a professora só age de forma rígida porque, segundo esse discurso, as crianças ainda não aprenderam a se comportar da forma correta. Se elas já fossem capazes de se autocontrolar, não seria necessário lidar dessa forma com suas ações. Como elas ainda não o são, é importante uma condução firme de suas condutas, a fim de que elas apaguem algumas marcas infantis (como a agitação, as conversas e as brincadeiras "fora de hora") e adéquem-se às normas escolares. Isso ocorre porque uma das normas estabelecidas pelo dispositivo de antecipação da alfabetização se refere à necessidade da disciplina para aprender a ler e a escrever. Para garantir a alfabetização, é preciso deixar de lado algumas 
marcas produzidas pelo dispositivo de infantilidade para ser o(a) aluno(a) que se espera no primeiro ano do Ensino Fundamental. É preciso deixar de lado certas características de um(a) infantil-bruxo(a), para ser o(a) aluno(a)-fada que se espera nesse currículo.

Assumir a posição de sujeito bruxa, no caso dos(as) infantis, refere-se a não se comportar conforme estabelecido pelas regras disciplinares da escola, a não ter se tornado ainda o(a) aluno(a) que se espera no Ensino Fundamental. Assim, quando uma criança conversa durante a aula ou não faz suas atividades para brincar, ela assume a posição aluno(a)-bruxo(a) e faz com que a professora assuma a posição rígida, ativando uma série de procedimentos, tais como tirar o recreio daqueles(as) que se comportaram mal, enviar bilhetes para casa ou conversar com as famílias, para que as crianças sejam castigadas. Esses procedimentos são considerados como integrantes de uma técnica do castigo, por meio da qual se espera criar um(a) aluno(a)-fada, que segue as regras e se comporta bem, já que o dispositivo da antecipação da alfabetização acionado no currículo investigado opera com um discurso que considera a disciplina como algo imprescindível para se alfabetizar.

Porém, esses procedimentos são os menos sutis dentre aqueles utilizados para produzir alunos(as)-fadas, já que eles apresentam explicitamente aquilo que se quer e punem aqueles(as) que não se comportam adequadamente. Para ser uma boa bruxa - assim como para exercer adequadamente o poder e governar os outros -, é preciso astúcia e atenção aos detalhes. Dessa forma, a professora-bruxa não prescinde do seu "caldeirão" para produzir pequenos(as) alunos(as)-fadas, pois caldeirões são elementos essenciais na cozinha de uma bruxa moderna, como aponta Bird (2004), no livro Manual prático de bruxaria em onze lições ${ }^{8}$. Nesse caldeirão, ela coloca o nome daqueles(as) que não estão agindo adequadamente, para que eles(as) tenham a oportunidade de refletir sobre suas ações e modificá-las.

Comumente, a professora-bruxa avisa: "Eu vou colocar nomes no caldeirão da bruxa de quem ficar conversando" (Diário de campo, 25 de abril de 2013) ou diz que vai

anotar esse nome aqui no caldeirão da bruxa para as crianças que estão conversando muito terem um momento de conversa com a professora. Talvez a criança precise perder um momento que seja de brincadeira, ou o recreio, ou a educação física, porque está brincando na hora da aula.

\footnotetext{
${ }^{8}$ Este era um dos vários livros que havia na biblioteca da escola com a temática das bruxas.
} 
Ela faz suspense e continua: "Deixa eu ver quem vai ter o nome no caldeirão da bruxa. Quem vai ser o primeiro". As crianças ficam quietas, esperando para ver se algum(a) colega vai conversar. Como ninguém fala, a professora prossegue a aula com seu caldeirão vazio (Diário de campo, 02 de maio de 2013). No uso do caldeirão, há ainda o procedimento de ameaça da bruxa-rígida, mas há também o aspecto da brincadeira e do lúdico, procedimentos utilizados para produzir fadas bem-comportadas e conseguir a atenção considerada adequada para o trabalho de alfabetizar. Assim, dois procedimentos são adotados: a ameaça de perder o momento da brincadeira, mas também o jogo de brincar e a fantasia acionados pela professora-bruxa para encantar os(as) infantis. A ambiguidade que tanto caracteriza as bruxas é acionada no currículo investigado a fim de governar os(as) infantis.

Outros procedimentos também são utilizados para incentivar que essas fadinhas sejam cada vez mais brilhantes no currículo investigado. A professora-bruxa pode, por exemplo, passar "um creme que brilha nos alunos e alunas para eles serem iguais estrelas". Diante da perspectiva de ter tal "poção mágica" passada em seus corpos, os(as) infantis se empolgam, se divertem, cheiram o creme passado e tentam se comportar de forma brilhante, ou seja, agindo conforme as regras estabelecidas nesse currículo (Diário de campo, 28 de junho de 2013). A professora-bruxa também pode usar de suas palavras mágicas para incitar o brilho infantil, como quando afirmou que "a estrelinha da Brenda está brilhando hoje". As crianças se empolgam com a ideia e perguntam se também estão brilhando. Diante do questionamento de outras crianças, a bruxa afirma que suas estrelinhas estão brilhando também (Diário de campo, 18 de junho de 2013). Por meio desses procedimentos, a professora-bruxa marca as(os) alunas(os)-fadas como aquelas(es) que brilham. Estabelece, assim, um modelo a ser seguido pelos(as) demais alunos(as), se quiserem ser considerados (as) fadas no currículo escolar.

Uma norma é acionada aqui para se produzir um(a) infantil que se adéque à escola. Cria-se, nesse currículo, uma situação em que se mistura uma técnica de dominação entendida como aquela que outros exercem sobre a ação de alguém a fim de que esse alguém aja de determinada forma - com uma técnica de si: aquela que leva os indivíduos a “operarem um certo número de operações sobre os seus corpos, sobre as suas almas, sobre o seu próprio pensamento, sobre a sua própria conduta, e isso de tal maneira a transformaram-se a eles próprios" (Foucault, 1993, p. 207). A técnica de dominação aqui 


\section{pro.posições}

acionada é a técnica do modelo, que define quem brilha e quem não brilha. Já a técnica de si é a técnica do julgamento, por meio da qual a criança tem que se julgar e, com base nisso, mudar ou manter sua postura.

Técnicas e procedimentos como esses fazem com que ocorram alguns diálogos entre as crianças-fada, como: "Sarah, para de conversar, se não seu nome vai para o caldeirão" (Diário de campo, 28 de junho) ou "Continua assim que seu nome vai pro caldeirão" (Diário de campo, 31 de agosto). Faz também com que a criança dobre sobre si mesma essa posição. Dessa maneira, quando a bruxa ameaça, dizendo: "criança que não presta atenção, quando pedir ajuda eu não dou não", a criança-fada responde: "Eu to prestando mil atenções" (Diário de campo, 04 de maio). O discurso que ensina que fadas são boas e as apresenta como modelo a ser seguido faz com que as crianças se enquadrem nas normas escolares. Quando se acionam seres mágicos, suas marcas e condutas nesse currículo, o cumprimento dessas normas passa a ser permeado não pelo medo, mas pela alegria e pela fantasia.

Ser bruxa é também assumir o papel daquela que conduz. Desde as moiras na mitologia grega ou as parcas na mitologia romana, seres místicos estão envolvidos com a construção do destino humano ${ }^{9}$. Eles tramam esse destino e garantem a nossa sorte. Em contos infantis, muitas vezes as fadas são responsáveis pela condução do destino de uma criança, assim que ela acaba de nascer, como ocorre em A Bela Adormecida. Na mitologia celta, são as bruxas que exercem essa atividade de conduzir a vida humana muito além daquilo que pode ser entendido (Trindade, 2008). No currículo investigado, a professorabruxa também assume esse lugar de condutora, definindo não somente o que será feito na sala de aula, mas também se responsabilizando ativamente pela vida e, sobretudo, pela alfabetização dos(as) infantis-fadas que estão sob sua responsabilidade.

A professora-bruxa assume, então, outra posição de sujeito, a posição bruxacondutora. Ela procura cuidar de cada criança, garantindo a alfabetização de todos(as) e de cada um(a) das(os) alunos(as)-fadas daquele currículo. Para isso, ela busca conhecer cada um(a) deles(as), seu passado (por meio de conversas com seus familiares), seu presente (por meio das ações feitas por ela e de diferentes diagnósticos) e seu futuro (traçando as metas

\footnotetext{
${ }^{9}$ A história das moiras estava presente no livro Mitos gregos (Kimmel, 2008), disponível na biblioteca da escola, embora não fosse manuseado pelas crianças da turma investigada, já que a letra usada em sua escrita não era maiúscula.
} 


\section{pro.posições}

que devem ser por elas alcançadas). A professora-bruxa-condutora cuida do seu rebanho de fadinhas, por meio daquilo que Foucault (2008) nomeou como o poder pastoral. Esse poder "é um poder de cuidado" (p. 168), pois, por meio dele, o pastor deve cuidar do rebanho, garantir sua alimentação, sua instrução, sua saúde e sua boa condução ao longo da vida. Assim, a professora, ao assumir essa posição, precisa cuidar de cada criança, conhecendo-a e orientando-a ao longo do seu processo de alfabetização.

Para isso, a bruxa-condutora aproxima-se da bruxa-rígida para garantir a ordem, considerada como fundamental para o processo de alfabetização. Mas a bruxa precisa também acionar outras técnicas para efetivar a alfabetização. Como bruxa, ela conhece as crianças, os métodos de alfabetização, as diferentes teorias, os diversos materiais didáticos e os aciona para produzir o encantamento pela alfabetização e por meio dela. Assim, algumas palavras mágicas são acionadas no currículo para garantir esse fim, a exemplo das parlendas, que servem como fio condutor para muitas práticas desenvolvidas nesse currículo. Por meio delas, a bruxa-condutora ensina os(as) alunos(as)-fadas a estabelecer relações entre as letras e seus sons, fazendo com que, gradativamente, eles(as) se alfabetizem. Se uma parlenda se mistura aos seres mágicos, a ação para alfabetizar torna-se ainda mais eficiente. Assim, uma parlenda que tem como temática a casa da bruxa é utilizada nesse processo de ensinar o código escrito.

As crianças devem refletir sobre a escrita das palavras e copiar em seu caderno os seguintes versos: "CASA DE BRUXA TEM/SAPO, MORCEGO E CORUJA/PRA QUE É QUE SERVE A VASSOURA/SE A CASA DELA É TÃO SUJA?” (Diário de campo, 22 de agosto de 2013). Significados que associam a bruxa à sujeira e aos animais místicos, como sapo, morcego e coruja, são acionados no momento em que se quer ensinar a ler e escrever. Ensina-se a refletir sobre a escrita de cada palavra, mas também se faz circular nesse currículo alguns sentidos vinculados a bruxas. Ao final da escrita e leitura da parlenda, Adryan pergunta: "mas, pra que serve a vassoura, então?”. A professora retoma a pergunta dele, repetindo-a para a turma. Alguns(algumas) falam que é para varrer, mas a professora completa, perguntando: “mas se a casa está suja, ela está varrendo a casa?’. Nesse momento, Eric diz: "Pra ela voar". A professora confirma e fala: "Ah, ela usa para voar. Ela gosta de sujeira.”. Ao entrar no jogo que traz seres fantásticos para o universo da alfabetização, as crianças-fadas não se contentam apenas em copiar a parlenda. Elas querem mais informações sobre o que ocorre com esses seres mágicos, e as incorporam às suas 


\section{pro.posıções \\ e-ISSN 1980-6248}

10.1590/1980-6248-2016-0004

fantasias e à sua imaginação. Se, geralmente, há reclamações quanto ao tamanho de textos a serem copiados, nesse dia, Mateus questiona se o texto é só aquele mesmo e diz que ele é pequenininho. $\mathrm{O}$ uso da fantasia parece ser um procedimento para garantir que as criançasfadas sejam conduzidas no processo de alfabetização sem queixas, com diversão e alegria.

As palavras "bruxa" e "fada" também são utilizadas em diferentes contextos como palavras mágicas para ensinar a ler e escrever. A fada é misturada com outras palavras que também começam com a letra " $F$ " em um caça-palavras que precisa ser desvendado pelas crianças em processo de alfabetização para desenvolver diferentes habilidades relacionadas à leitura e à escrita.

\section{Imagem 1: atividade colada no caderno de uma das crianças} (Diário de campo, 25 de fevereiro de 2013)

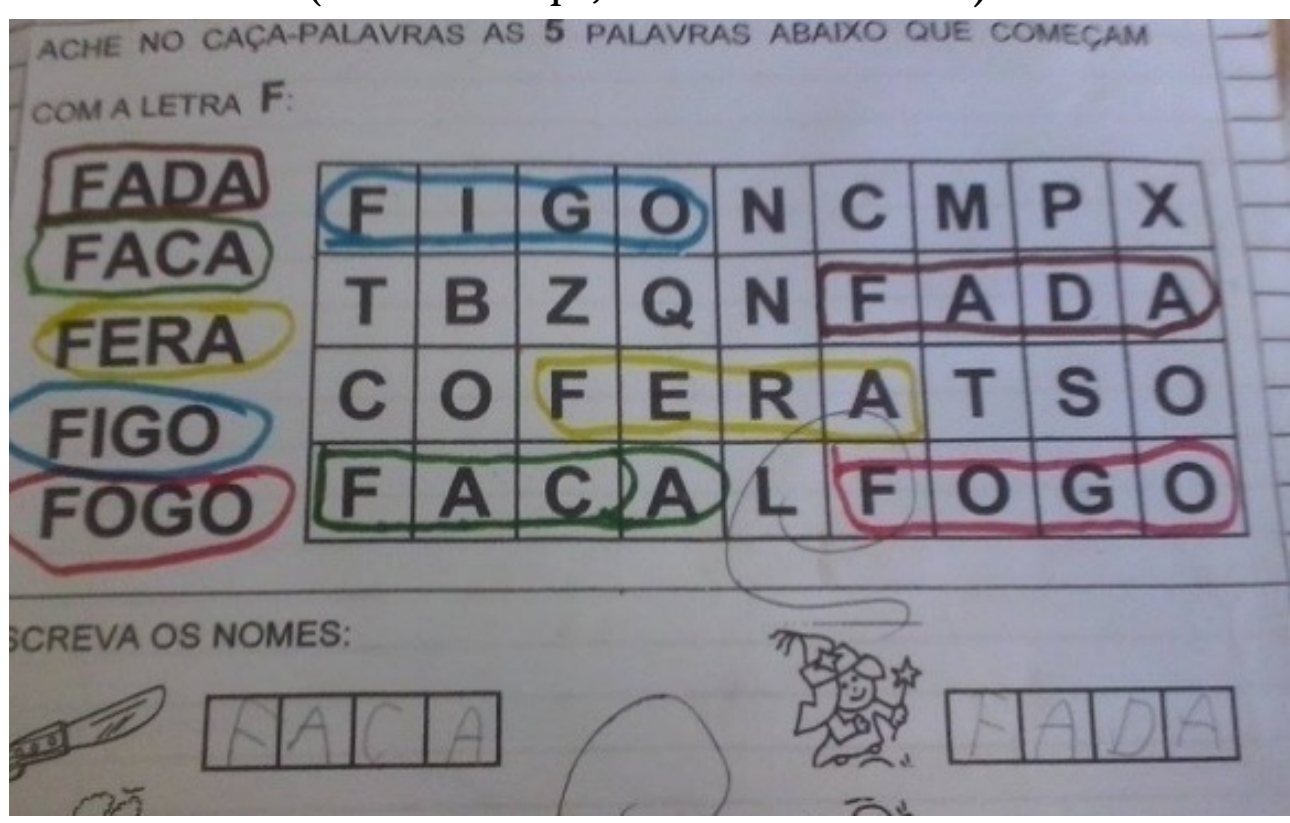

Fonte: material produzido pela professora observada e registrado pelas autoras.

Em uma atividade aparentemente vinculada aos métodos tradicionais, na qual é preciso localizar palavras que comecem com a mesma letra, o elemento mágico funciona como um atrativo especial para as crianças. Na hora de marcar a atividade, Sarah pergunta se pode marcar com canetinha colorida, algo normalmente não permitido. A professora diz: "Hoje vou abrir uma exceção. Mas só pode passar para contornar as palavras e depois de me mostrar" (Diário de campo, 25 de fevereiro de 2013). Como pequenas fadas, elas não apenas fazem a atividade como a destacam com cores especiais, tornando mais colorido e leve algo que normalmente é vinculado ao tradicional. $\mathrm{Na}$ mesma direção, as crianças-fadas divertem-se, em outro momento, trocando adesivos presentes no caderno de 


\section{pro.posıções \\ e-ISSN 1980-6248}

Julia e que têm uma fada como tema principal (Diário de campo, 27 de abril de 2013). A bruxa-condutora, que precisa garantir a alfabetização de todos(as) e de cada um(a), usa esses seres mágicos que despertam interesse infantil para garantir o engajamento deles(as) a essas atividades.

Com o mesmo objetivo, a bruxa também é acionada para auxiliar no processo de alfabetização. Seu caldeirão (já utilizado em outros momentos para garantir a ordem na sala de aula) é mobilizado novamente para que se "Forme[m] palavras que comecem com a letra S usando as sílabas que estão dentro do caldeirão" (Diário de campo, 12 de junho de 2013). Uma bruxa de feições suaves e delicadas é colocada ao lado do caldeirão, como se estivesse misturando as sílabas. Assim como ocorre com a fada, a bruxa é aqui acionada para mesclar uma atividade aparentemente tradicional com a fantasia, a fim de garantir a atenção do rebanho de fadinhas, consolidando seu processo de alfabetização. O dispositivo de antecipação da alfabetização opera, então, mesclando dois procedimentos, a fim de atingir seu objetivo. Poemas e textos envolvendo bruxas, como o que segue, também estão presentes no currículo investigado (Diário de campo, 17 de agosto de 2013).

\section{Imagem 2: Texto entregue para as crianças}

(Diário de campo, 17 de agosto de 2013)

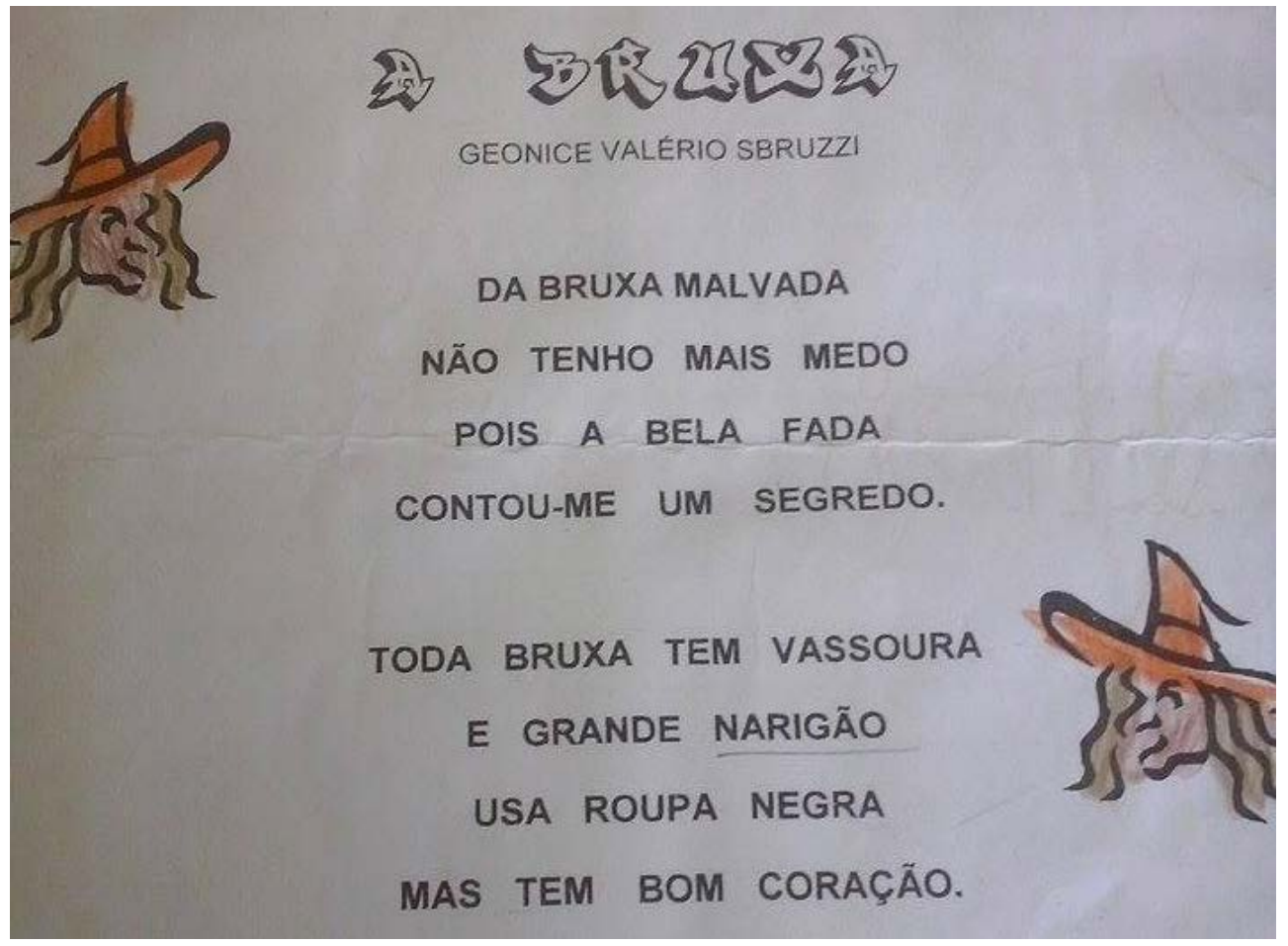

Fonte: atividade produzida pela professora e registrada pelas autoras. 
Diferente da parlenda, que visava a ensinar a escrita das palavras, esse poema é usado para trabalhar a interpretação de textos. A professora explora o título, o nome da autora, o segredo contado pela bela fada. Mas o que chama a atenção das crianças são outras coisas. Chama a atenção o modo como as letras estão dispostas no título do poema e que é identificado por Eric como "sendo chinês". Chama a atenção o nome diferente de quem escreveu, que levanta dúvidas quanto ao fato de ser uma mulher ou um homem. Chama a atenção o desenho. Ainda que se queira ensinar o que são versos e estrofes, as crianças-fadas têm sua atenção despertada por outros elementos presentes no texto apresentado. Enquanto a professora se preocupa com o conteúdo, as crianças estão preocupadas com a forma. Porém, a bruxa-condutora sabe se apropriar desses elementos para garantir a atenção dos(as) infantis. A fim de produzir uma criança alfabetizada, a docente não despreza esses elementos, levando-os para a sala de aula e dando atenção àquilo que as crianças-fadas querem dizer. A opinião de cada uma, o modo como se expressam e suas emoções são consideradas no processo de alfabetização, para que nenhuma fada se perca pelo caminho, para que todas concluam o primeiro ano atingindo a meta desse currículo: a alfabetização. Agindo como uma bruxa que "conhece a natureza, as ervas e diferentes maneiras de produzir encantamentos" (Trindade, 2008, p. 10), a docente sabe usar esses elementos para produzir a alfabetização.

Se a bruxa é, em outro texto, apresentada como alguém que não cuida da limpeza de sua casa, aqui se altera uma das características mais comumente associadas a ela ao longo

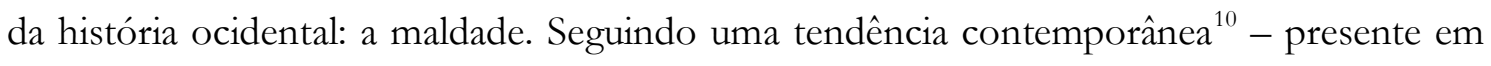
diferentes artefatos culturais - que não trata os(as) "vilões(vilãs)" apenas como seres maldosos, esse texto apela para o "bom coração" das bruxas. Talvez para cativar os(as) infantis destes tempos seja necessária não uma bruxa malvada e apavorante, mas uma bruxa que usa a magia para seduzir e encantar, em vez de maltratar e amedrontar.

Nos contos de fadas tradicionais, era instaurada uma "pedagogia do medo" que, por meio do terror, buscava assustar os(as) infantis com o objetivo de melhor regulá-los(as) (Hillesheim \& Guareschi, 2006). Hoje são outros os procedimentos usados para conduzir condutas infantis. Sem prescindir completamente de elementos "maldosos", a fantasia e a imaginação são acionadas nesse currículo para alfabetizar mais e melhor. Afinal, vivemos

\footnotetext{
${ }^{10}$ Exemplos dessa releitura podem ser vistos em filmes como Shrek (2001), Malévola (2014) e em releituras de contos clássicos, como A verdadeira história dos três porquinhos (Scieska, 2005).
} 


\section{pro.posiçcões}

em um tempo em que a infância se modifica e, por isso, é importante acionar outros elementos para que o dispositivo da infantilidade continue a funcionar. Além disso, é preciso operacionalizar uma multiplicidade de recursos para garantir a eficiência do dispositivo de antecipação da alfabetização. Assim, as fadas também são chamadas para garantir os efeitos desses dois dispositivos no currículo investigado. Isso não se faz, porém, sem conflitos, como mostramos no tópico a seguir.

\section{Fadas-transgressoras para movimentar o currículo e estruturar os dispositivos da infantilidade e da antecipação da alfabetização}

Alunos(as)-fadas, que se comportam bem, cumprem as regras e aprendem a ler e escrever ainda no primeiro ano do Ensino Fundamental são uma das demandas desse currículo. Para produzir essas fadas, muitas vezes a bruxa entra em ação. Contudo, às vezes, a própria fada é acionada para produzir outros(as) iguais a si. Nesse sentido, o dispositivo de infantilidade entra em conflito com o dispositivo de antecipação da alfabetização que, para efetivar-se, precisa fazer com que as crianças deixem de lado algumas marcas infantis. Em alguns momentos, o dispositivo de antecipação da alfabetização, "opõe-se às forças ativas da infância" (Corazza, 2002b, p. 72), atuando para criar um(a) infantil que se apresente como "educado, racional, consciente, sujeitado, moralizado" (Corazza, 2002b, p. 72). Assim, as fadas aparecem como representação do bem demandado pelo dispositivo da infantilidade, em oposição às crianças-bruxas.

Nem todas as fadas, entretanto, são bem-comportadas como essas que se pretendem criar nesse currículo. Aliás, de modo geral, as fadas das histórias também não são tão bem-comportadas assim. Há, é claro, fadas boas, como Fauna, Flora e Primavera, as fadas-madrinhas de $A$ Bela Adormecida. Mas há também aquelas agitadas e que causam mais confusão do que paz, como Sininho (Tinker Bell), Clara Luz ${ }^{11}$ ou as Fadas

\footnotetext{
${ }^{11}$ Clara Luz é a personagem principal do livro A fada que tinha ideias (Almeida, 1985).
} 


\section{pro.posições}

Mordentes ${ }^{12}$. Essas se aproximam bastante das crianças fadas-transgressoras que vivenciam o currículo investigado.

A posição de sujeito criança-fada tem, portanto, duas marcas: a primeira é a do(a) aluno(a) disciplinado(a) - criação do caldeirão e dos brilhos da professora bruxa-rígida -; a segunda remete à fada que pensa fora daquilo que está estabelecido no currículo e que faz inusitadas conexões. É importante acionar essas duas posições de sujeito no currículo investigado, pois circula na contemporaneidade a ideia de que a criança de hoje "prefere as aventuras de um marciano às histórias de uma fadinha chata e melosa" (Kohan, 2013, p. 56). Se os mecanismos da "pedagogia do terror" parecem não funcionar mais na atualidade, aqueles que associam as crianças à afetividade ou ao carinho excessivos também parecem ter pouco efeito. Dessa maneira, é preciso trazer outras características das fadas para o currículo, para disponibilizar variadas técnicas, a fim de atuar no governo dos(as) infantis.

A posição de sujeito fada-transgressora é ocupada pelos(as) infantis quando vivem uma "infância que resiste aos movimentos concêntricos, arborizados, totalizantes" (Kohan, 2007, p. 94). Ela emerge nos momentos em que os(as) infantis dão respostas completamente distintas daquelas planejadas pelo currículo escolar. Ocorre, por exemplo, quando se está ensinando sobre números ordinais, e é dada uma atividade para as crianças em que há alguns vagões de trem para que seja identificada sua posição. Quando se pergunta: "Em que posição o vagão azul está?”, Sarah responde: “Torto” (Diário de campo, 10 de maio de 2013). Ou no momento em que se conta uma história na qual há palavras em inglês e a docente pergunta: "Em inglês, amor é”... Evellyn responde: "Lindo!" (Diário de campo, 20 de junho de 2013).

Os(as) infantis fadas-transgressores(as) também usam os saberes vinculados às disciplinas escolares para fazer outras coisas. Realizam seus encantamentos, transformando aquilo que lhes é dado em novos materiais e novas vivências. Comportam-se como Clara Luz, do livro $A$ fada que tinha ideias, que afirma que não gosta de aprender pelos livros, não por preguiça, mas porque não gosta do mundo parado e porque acredita que "quando ninguém inventa nada, o mundo fica parado" (Almeida, 1985, s.p.). Assim, eles(as) inventam novos significados para a alfabetização naquele currículo. Fernando, Caio, Gustavo e João, por exemplo, usam o saber sobre as sílabas que é amplamente ensinado

${ }^{12}$ Fadas mordentes são personagens da série Harry Potter, que também fazia parte da biblioteca da escola e despertava interesse nas crianças, ainda que elas não fossem "autorizadas” a pegar esses livros. 


\section{pro.posições}

nesse currículo para discutir coisas que são "de Deus" e coisas que são "do capeta", mas eles não falam a palavra "capeta", apenas apontam para o chão. Fernando diz que quem falar a palavra vai levar um cocão. Começam a brincar de só falar as sílabas iniciais: $\mathrm{Ca}$, para indicar capeta, Di, para indicar diabo, De para falar de demônio... (Diário de campo, 10 de agosto de 2013).

A atração que o diabo exerce sobre as crianças-fadas - percebida em outras situações, como quando Nicolas afirma que Ben 10 quer dizer 10 demônios ou quando um grupo de crianças em um momento de brincadeira livre faz uma votação para descobrir como o diabo se tornou diabo ${ }^{13}$ - mostra o flerte dos(as) infantis com essa figura demoníaca. Essa é uma das características desse ser que é, "por um lado, misterioso, fascinante, e, por outro, perigoso, impuro" (Corazza, 2002b, p. 61). As fadas, que, teoricamente, deveriam ser boas, mas muitas vezes também trazem em si a ambiguidade (Trindade, 2008, p. 91), aproximam-se do diabo para bagunçar o currículo e produzir outros modos de usar os saberes nele veiculados.

Em outra situação, Adryan conta a uma das pesquisadoras que Eric chamou Julia de coisa que não pode. A pesquisadora pergunta do que Eric chamou a colega. Adryan diz "Go" e pergunta se a pesquisadora entendeu. Diante da resposta negativa, o menino avisa que vai falar por sílabas porque não pode falar a palavra toda. Olha para os lados e sussurra: GOS-TO-SA (Diário de campo, 11 de setembro de 2013). Essas situações mostram que, com base naquilo que o currículo ensina, os(as) infantis-fada produzem outros saberes no currículo escolar. Muitas vezes, esses saberes não são valorizados pela escola. Em outros momentos, eles servem para transgredir as regras e fazer aquilo que é oposto ao que se ensina nesse currículo. A posição de sujeito aluno(a)-alfabetizado(a) que se quer construir aparece, então, com marcas distintas daquelas que se esperam no currículo escolar.

A posição de sujeito fada-transgressora também é ocupada por aqueles(as) que não aprendem conforme o que está estabelecido pelas teorias de alfabetização que gozam de prestígio no currículo investigado, particularmente pelo discurso da psicogênese da língua escrita. Nesse momento, estar na posição de sujeito infantil fada-transgressora significa pensar diferente do que se pensa, mas implica também ser privado de algumas atividades

${ }^{13}$ Essas situações foram observadas e registradas no diário de campo, respectivamente, em 22 de agosto de 2013 e 03 de dezembro de 2013. 


\section{pro.posições}

prazerosas em função de sua não adaptação às regras escolares. É o que ocorre com aquelas crianças que não estão alfabetizadas quando a maioria das crianças já está e, por isso, ficam com a professora no horário da educação física. Essas infantis-fada nem sempre reconhecem sua posição de não saber e operam com a ideia de que estão sendo punidas, não por serem fadas e pensar diferentemente, mas por serem bruxas e se comportarem mal. É o que ocorre quando Karen pergunta se vai ficar sem educação física porque se comportou mal, e a professora explica que, no caso dela, vai ficar na sala para aprender mais (Diário de campo, 07 de agosto de 2013).

Em função das constantes classificações e de ficar várias vezes na sala para “aprender mais", a menina acaba assumindo o lugar de quem não sabe e passa a ser também identificada dessa forma por seus(suas) colegas. Em outra situação, Karen diz que não sabe fazer uma atividade. A docente explica para ela fazer apenas o que sabe, que logo em seguida irá ajudá-la. Luiz interfere e diz: "ela não deve saber nada" (Diário de campo, 18 de setembro de 2013). Em outro momento, Gustavo comenta que conhece uma aluna do terceiro ano que não sabe ler. Yasmin afirma que a aluna grande não sabe ler, assim como a Karen, e Luiz completa, dizendo que Karen não sabe ler nenhuma palavra ainda. Karen fica triste com os comentários, mas não fala nada (Diário de campo, 11 de setembro de 2013). Ser colocada na posição de não saber, em outros casos, gera revolta nos(as) infantis-fadas-transgressores(as), como quando Brenda pergunta como deveria escrever o nome de sua cachorra, Pretinha. Eric se intromete na conversa e diz: "você não sabe escrever até hoje?”. A menina fica brava e fala: "Eu sei que começa com P, mas o resto eu não lembro, por isso perguntei pra professora e não pra você" (Diário de campo, 11 de maio de 2013).

O currículo investigado, ao estabelecer como e quando as crianças devem aprender, cria hierarquizações que afetam as infantis-fada que não pensam conforme esse currículo. Todavia, "quem ousa antecipar o que pode pensar uma criança? Quem ousa prever a força que pode ter o pensamento de uma criança? Quem ousa dizer que, tendo em conta a idade, a criança pensará isso ou aquilo?” (Kohan, 2007, p. 19). Ao estabelecer respostas a essas questões, o currículo investigado, por operar com o dispositivo de antecipação da alfabetização, limita as possibilidades de vivência dos(as) infantis-fada, criando sentimentos de tristeza e impotência ou de hostilidade entre eles(as). Ensina-se, dessa forma, que ser infantil no sentido de ocupar a posição de quem não sabe é algo "mau", enquanto apagar 


\section{pro.posições}

certas marcas infantis para aprender a ler é algo "bom". Uma genealogia da moral que hierarquiza é acionada pelo dispositivo da infantilidade para dispor as crianças-fadas de certa forma nesse currículo (Corazza, 2002a).

Há que se registrar também que, à posição de sujeito infantil-fada, corresponde a professora-fada. Essa, diferentemente da bruxa, é doce e afetuosa e, muitas vezes, entra nas brincadeiras das crianças-fada. $\mathrm{O}$ afeto aparece como uma marca considerada fundamental pelas outras professoras-bruxas da escola para a fada-alfabetizadora de crianças de 6 anos, conforme apontado pela coordenadora da escola (Diário de campo, 23 de abril de 2013). Esse afeto também é apreciado pelas crianças-fada que abraçam, beijam, dão presentes e cartinhas para a fada-alfabetizadora no seu dia, deixando-a emocionada (Diário de campo, 15 de outubro de 2013). Faz também com que a professora se coloque, literalmente, ao lado de seus(suas) alunos(as) para ajudá-los(as) quando têm alguma dificuldade, como no momento em que Roberta divide a cadeira com Evellyn para auxiliá-la na cópia de um texto coletivo produzido pela turma (Diário de campo, 14 de maio de 2013)

O uso dos sentimentos aparece como um dos procedimentos usados pela professora para melhor conduzir os(as) infantis-fadas, como quando a docente afirma que aquele comportamento a está deixando magoada (Diário de campo, 11 de maio de 2013) ou quando afirma estar muito triste com a turma (Diário de campo, 03 de setembro de 2013). Ao mesmo tempo, os sentimentos - particularmente aqueles vinculados ao afeto vêm sendo apresentados como uma importante estratégia para o governo das professorasalfabetizadoras, pois, à medida que ensinam como elas devem se relacionar com as crianças, aumentam sua carga de trabalho (Paraíso, 2010b). Por serem afetuosas, elas devem se dedicar ao seu trabalho de forma intensiva, deixando de lado, inclusive, seus momentos de lazer para planejar mais e melhores atividades. É o caso da professora-fada pesquisada que, quando questionada sobre em que momentos planeja as atividades, responde: "Eu planejo muito em casa, porque aqui não tem jeito [risos]" (Entrevista com a docente, 16 de maio de 2013).

Embora haja na escola quatro horas semanais dedicadas ao planejamento, na maioria das vezes, a professora utiliza esse horário para ficar com crianças que não terminaram suas atividades ou que precisam, segundo a lógica imposta pelo dispositivo de antecipação da alfabetização, de "reforço" para consolidar as aprendizagens da língua 


\section{pro.posições}

escrita. Em outras situações, havia reuniões com famílias ou com a coordenação para discutir assuntos relacionados às crianças. Assim, o planejamento das atividades é realizado em casa. Como boa condutora de um rebanho de fadinhas-infantis, a professora "só pensa no seu rebanho e em nada além dele" (Foucault, 2008, p. 171).

Além da preocupação com a garantia da alfabetização das crianças-fadas, algo que também sobrecarrega a alfabetizadora-fada são as diferentes demandas presentes tanto no dispositivo de antecipação da alfabetização como em outros discursos contemporâneos sobre a educação das crianças de 6 anos que requerem muito trabalho por parte dela. A alfabetizadora-fada afirma "a gente faz formação de Português e falam que é para a gente trabalhar história, textos todos os dias. $\mathrm{Na}$ de Matemática fala para trabalhar material concreto todo dia... Haja tempo para tanta coisa!" (Diário de campo, 26 de setembro de 2013). Essa pressão sentida pela professora para trabalhar tantas coisas com as crianças também faz com que, na visão docente, as crianças fiquem mais agitadas. Tanto é assim que, em certa situação, ela comenta que naquele dia está mais light e as crianças também: "Acho que a gente que agita eles". (Diário de campo, 01 de junho de 2013). Parece haver uma compreensão de que a necessidade de ensinar tantos saberes e usar metodologias diversas cansa e agita os(as) alunos(as)-fadas, algo que não se deseja nesse currículo que opera com o dispositivo de antecipação da alfabetização, e demanda disciplina para se alfabetizar. Essa necessidade também cansa a alfabetizadora-fada, que se sente responsável por garantir às crianças-fada a melhor educação possível, ainda que, na maior parte do tempo, isso signifique sobrecarregar a si mesma e aos(às) infantis.

Em função dessas diversas demandas, às vezes, a alfabetizadora-fada se frustra por não conseguir agir conforme aquilo que está estabelecido nesses diversos discursos, como quando tentou fazer a reescrita da história Um amor de familia (Ziraldo, 1991), e as crianças não conseguiram copiar o texto produzido coletivamente. Por causa disso, a professora diz para uma das pesquisadoras, em tom triste: "Hoje foi um dia perdido. Eu exagerei". Perder um dia, tendo em vista a quantidade de coisas que precisa ser feita no currículo destinado às crianças de 6 anos, é considerado algo muito ruim, algo que causa profunda tristeza na professora. Após dizer isso, ela recolhe as atividades. Diante do questionamento de algumas crianças sobre o motivo para estar recolhendo as folhas, ela diz que não ficou brava com quem não terminou, pois sabe que essa era uma tarefa difícil. Ela diz que vai recolher para depois tentarem fazer de novo e também para compararem com outros 


\section{pro.posições}

momentos em que fizerem atividades como essas, para eles(as) perceberem o quanto evoluíram. As crianças, talvez percebendo a frustração da docente, ficam quietas, escutando-a, enquanto ela recolhe as folhas. A professora diz que está emocionada com esse comportamento deles(as) (Diário de campo, 20 de junho de 2013). Há uma solidariedade entre infantis-fada e fada-alfabetizadora que é construída no cotidiano da sala de aula e que se caracteriza como uma das mágicas do processo de alfabetização.

Outras mágicas também estão presentes ali, sobretudo a mágica de ensinar. Essa capacidade aparece como outra marca fundamental da fada-alfabetizadora, sendo reconhecida pelos(as) infantis-fada. Em certo momento, Karen diz, encantada: "professora, você sabe de tudo!". Adryan responde: "Se ela não soubesse, não seria professora". Três meninas afirmam que querem ser professoras quando crescerem (Diário de campo, 17 de setembro de 2013). Apesar de discursos diversos e pesquisas variadas que mostram que há cada vez menos atratividade na carreira docente (Gatti et al., 2013), no currículo investigado, a mágica proporcionada pela docente faz com que haja um desejo infantil de também ser professora.

Em outra situação, Luiz pergunta insistentemente se é para pegar o caderno. A docente afirma que eles estão com vício de caderno. O menino afirma: "Lógico, você só quer nos ensinar". A alfabetizadora-fada contrapõe: "Claro, eu sou uma professora" (Diário de campo, 20 de junho de 2013). Ensinar é o encantamento maior presente nesse currículo. Ainda que alguns discursos afirmem que um mestre que ignora determinado assunto pode fazer os outros aprenderem (Rancière, 2005), opera, no currículo pesquisado, o discurso pedagógico que considera que, para ensinar, dominar o saber que se pretende construir é fundamental.

Esse saber é apresentado pela alfabetizadora-fada como algo que vem da prática, da experiência. Quando questionada sobre por que sabe fazer os números tão depressa, ela explica: “'É o treino, a experiência” (Diário de campo, 02 de maio de 2013). Ao contar palitinhos rapidamente para separar em grupos de dez, ela fala: "como eu já contei muito na minha vida, eu já sei contar rapidão" (Diário de campo, 27 de abril de 2013). Dessa forma, a alfabetizadora-fada faz com que os saberes que ensina sejam apresentados aos(às) infantis-fada como algo simples, resultado de treino e experiência. O feitiço de aprender é apresentado como algo fácil de ser conseguido. Apresentar um feitiço como algo fácil 


\section{pro.posições}

aumenta o poder daquele(a) que o executa. Como afirma Melisandre, feiticeira da série de livros As crônicas de gelo e fogo, "quanto mais fácil o feitiço parecia, mais os homens temiam o feiticeiro" (Martin, 2007, p. 548). Assim, apresentar o feitiço do aprender como algo corriqueiro e que envolve apenas o treino serve para garantir que mais rapidamente os(as) infantis-fada se tornem capazes de realizá-lo.

A alfabetizadora-fada também se caracteriza por aprender com as crianças-fada. Mesmo que, na maior parte do tempo, eles(as) sejam considerados como ignorantes e marcados pela falta, há momentos em que seus saberes aparecem e ganham relevância no currículo investigado. Afinal, "não há ignorante que não saiba uma infinidade de coisas, e é sobre este saber, sobre esta capacidade em ato que todo ensino deve se fundar" (Rancière, 2005, p. 11). Quando a alfabetizadora-fada usa a parlenda "Se eu fosse um peixinho", um de seus artifícios mais comuns para alfabetizar, ela inicia dizendo que "Tem muita gente que já conhece”. Ela começa a cantar e as fadinhas a acompanham. Quando ela termina, Eric completa: “Tiriri pra lá, tiriri pra cá, a menina é feia e quer casar". Todos(as) da sala riem (Diário de campo, 09 de maio de 2013). A alfabetizadora-fada se coloca à disposição para ouvir aquilo que os(as) infantis-fada sabem. Nesse momento, quebra-se a hierarquia que impera no currículo investigado e que coloca a fada mais velha como responsável pela condução das aulas. Ela se aproxima das crianças-fadas, na medida em que se coloca na posição de não saber, que vem sendo constantemente construída para as crianças. Ainda que isso sirva, às vezes, para ter um maior controle sobre a sala e, nessa medida, governar os(as) infantis, consegue também produzir alegrias e momentos de descontração nesse currículo tão cheio de regras e saberes a serem ensinados e aprendidos.

Em outros momentos, a alfabetizadora-fada também se coloca no lugar infantil, quando brinca com as crianças, provocando divertimento e alegria. Nessas situações, ela se contagia com a fantasia dos(as) infantis-fada. Não se trata, contudo, de infantilizar-se "de voltar à nossa tenra idade, de fazer memória e reescrever nossa biografia, mas de instaurar um espaço de encontro criador e transformador da inércia escolar repetidora do mesmo" (Kohan, 2007, p. 98). Quando a alfabetizadora-fada se aproxima das(os) infantis-fada, temse a criação de momentos alegres no currículo do primeiro ano escolar, que desorganizam a lógica imposta e vivida na maior parte do tempo. 
Fica evidente, então, que acionar fadas e bruxas no currículo do primeiro ano que opera com os dispositivos da infantilidade e da antecipação da alfabetização parece ser um importante artifício para produção de sujeitos. É claro que não há uma homogeneidade nas posições de sujeito demandadas com base nesse artifício, tendo em vista a própria natureza desses seres que é marcada pela ambiguidade, pela dualidade, pela fluidez. Dessa forma, ser professora alfabetizadora de criança de 6 anos implica acionar os diferentes significados vinculados aos seres mágicos, que ora são malévolos e rígidos, ora são doces e afetivos, como mostramos ao longo do artigo. De modo semelhante, ser criança ou aluno(a) fada ou bruxa também se insere nessa cadeia discursiva marcada pela multiplicidade. Pode-se ser uma bruxa que burla as normas estabelecidas, uma fada que segue as regras e brilha no currículo ou uma fada transgressora, que pensa diferente e cria novos sentidos para os saberes da alfabetização.

As diferentes posições de sujeito demandadas para docente e crianças nesse currículo mostram, portanto, como o dispositivo de antecipação da alfabetização e o dispositivo de infantilidade disputam espaço na produção de sujeitos no primeiro ano do Ensino Fundamental. Eles, ora se aproximam, ora se distanciam, em alguns momentos mantendo e, em outros, apagando certas marcas infantis. Nesse processo, o currículo escolar passa a ser habitado por seres mágicos, que atuam tanto no governo como no autogoverno de infantis e docentes no primeiro ano do Ensino Fundamental. 


\section{pro.posições}

\section{Referências Bibliográficas}

Almeida, F. (1985). A fada que tinha idéias (12a. ed.). São Paulo: Ática.

Bird, M. (2004). Manual prático de bruxaria em onze lições. São Paulo: Ática.

Caldeira, T. (1988). A presença do autor e a pós-modernidade em antropologia. Novos estudos CEBRAP, 21, 133-157.

Clifford, J. (2008). A experiência etnográfica: antropologia e literatura no século XX. Rio de Janeiro: Editora UFRJ.

Corazza, S. (2001). O que quer um currículo? Petrópolis: Vozes.

Corazza, S. (2002a). Infância \& educação: era uma vez...quer que conte outra vez?. Petrópolis: Vozes.

Corazza, S. (2002b). Para uma filosofia do inferno na educação: Nietssche, Deleuze e outros malditos afins (1a. ed.). Belo Horizonte: Autêntica.

Correa, B. (2011). Educação infantil e ensino fundamental: desafios e desencontros na implantação de uma nova política. Educação \& Pesquisa, 37(1), 105-120.

Deleuze, G. (1992). Um retrato de Foucault. In G. Deluze, Conversações - 1972-1990 (pp. 127-147). São Paulo: Editora 34.

Foucault, M. (1993). Verdade e subjetividade. Revista de Comunicação e Linguagem, 19, 203223.

Foucault, M. (1995). O sujeito e o poder. In H. Dreyfys, \& P. Rabinow, Michel Foucault: uma trajetória filosófica para além do estruturalismo e da hermenêutica. (pp. 231-249). Rio de Janeiro: Forense.

Foucault, M. (1997). Resumo dos Cursos do Collège de France. Rio de Janeiro: Zahar.

Foucault, M. (2000). Sobre a história da sexualidade. In M. Foucault, Microfísica do poder (pp. 243-276, Roberto Machado, org. e trad.). Rio de Janeiro: Graal.

Foucault, M. (2004). 1984 - Foucault. In M. Foucault, Ditos e escritos V: ética, sexualidade, política (pp. 234-239). Rio de Janeiro: Forense.

Foucault, M. (2008). Segurança, território, população: curso no Collège de France (1977-1978). São Paulo: Martins Fontes. 
Hillesheim, B., \& Guareschi, N. (2006, janeiro/junho). Contos de fada e infância(s). Educação e Realidade, 31(1), 107-126.

Kimmel, E. Mitos gregos. São Paulo: Martins Fontes, 2008.

Kohan, W. (2007). Infância, estrangeiridade e ignorância - ensaios de filosofia e educação. Belo Horizonte: Autêntica.

Kohan, S. (2013). Escrever para crianças: tudo o que é preciso saber para prodųir textos de literatura infantil. Belo Horizonte: Gutemberg.

Martin, G. (2007). Os reinos do caos. Lisboa: Saída de Emergência.

Pansini, F. Marin, A. (2011). O ingresso de crianças de 6 anos no ensino fundamental: uma pesquisa em Rondônia. Educação \& Pesquisa, 37(1), 87-103.

Paraíso, M. (2010a). Apresentação. In M. Paraíso (Org.), Pesquisas sobre currículos e culturas: temas, embates, problemas e possibilidades. Curitiba: CRV.

Paraíso, M. (2010b). O currículo entre a busca por "bom desempenho" e a garantia das diferenças. In A. Dalben, J. Diniz, L. Leal, \& L. Santos (Orgs.), Convergências e tensões no campo da formação e do trabalho docente: currículo, ensino de educação física; ensino de geografia; ensino de história; escola, família e comunidade (pp. 132-152). Belo Horizonte: Autêntica.

Paraíso, M. (2014, setembro, 18 a 21). Currículo, cultura e diferença: “Gabriel e eu” ou "o amor é o signo”. In 11 Colóquio sobre Questões Curriculares, VII Colóquio Luso Brasileiro de Currículo e I Colóquio Luso-Afro-Brasileiro sobre Questões Curriculares. Braga, Portugal.

Queirós, B. (1988). Onde tem fada, tem bruxa. São Paulo: Moderna.

Rabinow, P. (2002). Antropologia da razãa. Rio de Janeiro: Relume Dumará.

Rancière, J. (2005). O mestre ignorante: cinco lições sobre a emancipação intelectual. Belo Horizonte: Autêntica.

Scieska, J. (2005). A verdadeira história dos três porquinhos. São Paulo: Companhia das Letrinhas.

Silva, M. (2005). O curriculo de Harry Potter. Monografia, Faculdade de Educação, Universidade Federal de Minas Gerais, Belo Horizonte. 
Silva, T. T. (1995). Currículo e identidade social: territórios contestados. In T. T. da Silva, Alienígenas na sala de aula: uma introdução aos Estudos Culturais em Educaşão (pp.190207). Petrópolis: Vozes.

Silveira, R. (2002). Professoras que as histórias nos contam. Rio de Janeiro: DP\&A.

Trindade, N. (2008). A bruxa nos contos de fadas. Dissertação de Mestrado em Educação, Arte e História da Cultura, Universidade Presbiteriana Mackenzie, São Paulo.

Ziraldo (1991). Um amor de família. São Paulo: Melhoramentos.

Submetido à avaliação em 18 de janeiro de 2016, aprovado para publicaşão em 01 de julho de 2016. 